\title{
DIETARY PATTERNS AND THEIR CHANGES IN EARLY CHILDHOOD
}

\author{
Eva Kudlová1, Dagmar Schneidrová ${ }^{2}$ \\ ${ }^{1}$ Institute of Hygiene and Epidemiology, First Faculty of Medicine, Charles University, Prague, Czech Republic \\ ${ }^{2}$ Institute of Child and Youth Health, Third Faculty of Medicine, Charles University, Prague, Czech Republic
}

\begin{abstract}
SUMMARY
Background: Early childhood is a critical period for shaping and influencing feeding behaviours which have implications for future health. Understanding the food consumption patterns and their shifts over time can provide guidance to health care providers and nutrition specialists who provide nutrition counselling and develop nutrition messages.

Objectives: To examine feeding patterns of 1-5 year old children and their changes with age.

Methods: A cross-sectional questionnaire study designed to obtain information on basic demographic indicators and feeding habits was conducted in Prague and all 13 regions of the Czech Republic. The carers of 1,130 children aged 1 to 5 years were approached in public places. Obtained data were computerized, descriptive statistics and t-tests for food intake frequency by age, breast-feeding status, sex, maternal education, and domicile were calculated. The difference was considered significant when $\mathrm{P}$ value was $<0.05$.

Results: The median duration of breast-feeding of children not breast-fed at the time of the interview was 9 months; $29.5 \%$ one-year olds were still breast-fed at the time of the interview. Median number of meals per day was 4 in 1 and 5 year olds and 5 in children 2 to 4 years old. The diet of one-year-olds, albeit with lower fruit and vegetable consumption and low fish consumption, was close to recommendations. The milk and milk products, fruit, vegetable, and poultry intake frequency significantly decreased with age. The meat and grains groups, smoked meat and meat products, sweets, and fried food intake frequency significantly increased with age. Fish consumption remained low. Higher vegetable intake frequency was associated with breast-feeding, maternal education, and female sex. Higher fruit consumption was associated with breast-feeding and living in Prague. Higher meat group intake frequency was associated with male sex.

Conclusions: Our data confirm that the dietary habits are formed early in the life. Enhancement of multi-channel delivery of nutrition messages for feeding of toddlers and pre-schoolers and for the improvement of family eating habits are needed.
\end{abstract}

Key words: eating patterns, food intake frequency, nutrition, toddlers, pre-school children

Address for correspondence: E. Kudlová, Institute of Hygiene and Epidemiology, First Faculty of Medicine, Charles University in Prague, Studničkova 7, 12800 Prague 2, Czech Republic. E-mail: ekudl@lf1.cuni.cz

\section{INTRODUCTION}

Health is indivisible, requiring holistic approaches throughout the individual's life. A healthy outcome at one life-stage determines health during its next stages. Growth and development of young children forms conditions for development during the school age period and in adolescence. This will be then carried through into adulthood and old age and will result in a lifetime of economic, social and personal benefits. There is a number of external factors influencing outcomes of the life stages. A balanced diet that provides optimum nutrition is crucial to every stage of development from pre-conception until later stages of life.

Poor nutrition is associated with a reduced resistance to disease, impaired physical and psychological development, and infant morbidity and mortality. An inadequate diet can lead to deficiency disorders and/or contribute to non-infectious chronic diseases including malignant and cardiovascular diseases, osteoporosis and dementia (1).

Early childhood is a critical period for shaping food consumption patterns which have implications for future health.
Appropriate feeding practices during early childhood stimulate psycho-social development, lead to good nutritional status and physical growth, reduce susceptibility to common childhood infections and improve resistance to cope with them $(2,3,4)$. Improved health outcomes in young children have long-lasting health effects throughout the life-span. This has been confirmed e.g. by findings of the Boyd Orr cohort studies analysing eating habits and influence of socio-economic factors conducted in 1937-1939 (5). Studies of this cohort conducted until today provide a unique opportunity to study various factors influencing eating habits from childhood until the old age. According to the Boyd Orr cohort studies, healthy eating habits in the old age are associated, among other factors, with diet rich in vegetables in childhood $(6,7)$.

Breast-feeding has a unique role in the nutrition of infants and young children for its short term as well as long term positive outcomes. Among the well documented benefits in developed countries are: a reduction in the risk of acute otitis media, nonspecific gastroenteritis, severe lower respiratory tract infections, atopic dermatitis, asthma, obesity, type 1 and 2 diabetes, child- 
hood leukaemia, sudden infant death syndrome (SIDS), and necrotizing enterocolitis (8). According to Fewtrell's review (9), breast-feeding also decreases the development of cardiovascular risk factors including hypertension and plasmatic lipid profile later in life.

The purpose of this study was to describe eating patterns and their changes from one to five years of age, a period when eating patterns that will influence health in later life-stages are constituted and to investigate selected factors which may influence them. The study was conducted within broader margins of project IGA MZ CR, NS9974-4, 2008-2010 Elaboration of guidelines for growth assessment of a breastfed child based on the comparison of growth of exclusively breastfed infants with current growth references for the Czech population and the WHO growth standards.

\section{MATERIALS AND METHODS}

A cross-sectional retrospective survey to assess child feeding habits was conducted in public places in Prague and all 13 regions of the Czech Republic. The study was approved by the Ethics Committee of Charles University in Prague, First Faculty of Medicine. Interviewers, students of the 5th year of the First Faculty of Medicine, approached women accompanied by a young child passing by in public places. If the woman was the primary carer (mother) of a one to five year old child and agreed to participate in the study, the interviewer completed with her a nutrition questionnaire collecting data on basic demographic variables, breast-feeding, meal patterns, food items intake frequency, most frequently taken beverages, and feeding wholemeal and low fat products. The questionnaire also included questions about problems with eating but these are not analysed in the presented paper. There was no question about the child's ethnic origin.

Food intake frequency categories were converted into daily food intake frequency as follows: once a day or more $=$ number of times per day, 5-6 times a week $=0.8 ; 4-5$ times a week $=$ $0.6 ; 3-4$ times a week $=0.5 ; 1-2$ times a week $=0.2 ; 1-3$ times a month $=0.1$; less frequently than once a month or not at all $=0$.

The collected data were computerized and software Statistica 9.1. (10) was used for their analysis. The data were separated by age. Descriptive statistics (mean, median, proportions, and standard deviation) was performed. Differences in daily food intake frequency by age, breast-feeding status at the time of interview, gender, maternal education, and location (Prague or elsewhere) were tested using t-test. The difference was considered significant when $\mathrm{P}$ value was $<0.05$.

\section{RESULTS}

Of 1,474 carers approached, 1,130 (76.7\%) were eligible and agreed with the interview. Except one child suffering from phenylketonuria excluded from the study and $13(1.2 \%)$ children with allergy not excluded from the study, no medically based dietary restrictions were reported. Questionnaires were completed for 1,130 children aged 1 to 5 years. Table 1 shows the sample characteristic.

Ever breast-fed were 1,067 (94.4\%) children. The mean duration of breast-feeding in children who were not breast-fed at
Table 1. Sample characteristic $(N=1130)$

\begin{tabular}{|c|c|c|}
\hline & Number & Proportion \\
\hline \multicolumn{3}{|l|}{ Child age distribution } \\
\hline 1 year (12-23 months) & 263 & $23.3 \%$ \\
\hline 2 years (24-35 months) & 228 & $20.2 \%$ \\
\hline 3 years (36-47 months) & 263 & $23.3 \%$ \\
\hline 4 years (48-59 months) & 240 & $21.2 \%$ \\
\hline 5 years (60-71 months) & 136 & $12.0 \%$ \\
\hline \multicolumn{3}{|l|}{ Child sex } \\
\hline Male & 581 & $51.4 \%$ \\
\hline Female & 549 & $48.6 \%$ \\
\hline \multicolumn{3}{|l|}{ Breastfeeding } \\
\hline Ever breastfed & 1067 & $94.4 \%$ \\
\hline Breastfed at the time of interview & 232 & $20.5 \%$ \\
\hline \multicolumn{3}{|l|}{ Domicile } \\
\hline Prague & 474 & $41.9 \%$ \\
\hline Other than Prague & 656 & $58.1 \%$ \\
\hline \multicolumn{3}{|l|}{ Maternal education } \\
\hline Primary & 146 & $12.9 \%$ \\
\hline Secondary & 636 & $56.3 \%$ \\
\hline University & 348 & $30.8 \%$ \\
\hline
\end{tabular}

the time of the interview was 9.9 months (median 9, s.d. 6.72). At the time of the interview $29.5 \%$ children aged 1 year and $7 \%$ children aged 2 years were still breast-fed. Also one 36 months old and one 42 months old child were breast-fed at the time of the interview. Mean number of breast-feedings during the past 24 hours before the interview was 4.3 (range 2-9; median 4; s.d. 2.05 ) in one-year-olds and 2.9 (range 1-5; median 2; s.d. 2.0) in two-year-olds.

Table 2 shows the meal frequency by age. Distribution of the number of meals other than milk in the past 24 hours approximately followed the bell curve with median 4 at 1 and 5 years and 5 in 2 to 4 year olds. In children aged 1 to 2 years, no statistically significant difference $(p>0.05)$ in the meal frequency of breast-fed and non-breast-fed was noted. At one year of age $18.8 \%$ of children got food other than milk only 2-3 times a day. Few individuals $(1-3 \%)$ aged $2-5$ years also received food other than milk 2-3 times a day. The proportion of children who did not take breakfast was low - it ranged between $1-2.6 \%$ by age

Table 2. Meal frequency by age (main meals and snacks)

\begin{tabular}{|l|c|c|c|c|}
\hline & \multicolumn{4}{|l|}{$\begin{array}{l}\text { Number of regularly taken meals other than milk per } \\
\text { day }\end{array}$} \\
\hline Age & Mean & s.d. & Median & Range \\
\hline 1 year $(\mathrm{N}=263)$ & 4.3 & 0.96 & 4 & $2-7$ \\
\hline 2 years $(\mathrm{N}=228)$ & 4.7 & 0.97 & 5 & $2-8$ \\
\hline 3 years $(\mathrm{N}=263)$ & 4.9 & 0.94 & 5 & $3-8$ \\
\hline 4 years $(\mathrm{N}=240)$ & 4.7 & 0.92 & 5 & $2-6$ \\
\hline 5 years $(\mathrm{N}=136)$ & 4.7 & 0.86 & 4 & $3-7$ \\
\hline
\end{tabular}


Table 3. Mean daily food intake frequency by age

\begin{tabular}{|c|c|c|c|c|c|c|c|c|c|c|}
\hline \multirow{3}{*}{ Foods } & \multicolumn{10}{|c|}{ Age } \\
\hline & \multicolumn{2}{|c|}{1 year $(\mathrm{N}=263)$} & \multicolumn{2}{|c|}{2 years $(N=228)$} & \multicolumn{2}{|c|}{3 years $(N=263)$} & \multicolumn{2}{|c|}{4 years $(\mathrm{N}=240)$} & \multicolumn{2}{|c|}{5 years $(N=136)$} \\
\hline & Mean & SD & Mean & SD & Mean & SD & Mean & SD & Mean & SD \\
\hline Milk group ${ }^{1}$ & 3.81 & 2.37 & 3.09 & 1.14 & 2.34 & 0.91 & 2.34 & 0.78 & 1.91 & 0.72 \\
\hline Milk ${ }^{1}$ & 2.40 & 2.3 & 1.60 & 1.03 & 0.91 & 0.71 & 0.84 & 0.34 & 0.71 & 0.36 \\
\hline Milk products except cheese & 0.76 & 0.29 & 0.77 & 0.26 & 0.76 & 0.27 & 0.73 & 0.30 & 0.57 & 0.30 \\
\hline Cheese & 0.66 & 0.34 & 0.71 & 0.25 & 0.67 & 0.8 & 0.71 & 0.30 & 0.63 & 0.28 \\
\hline Meat, fish, egg, pulses group & 1.44 & 0.68 & 1.56 & 0.54 & 1.70 & 0.94 & 1.63 & 0.71 & 1.51 & 0.51 \\
\hline Poultry & 0.44 & 0.25 & 0.41 & 0.21 & 0.37 & 0.22 & 0.33 & 0.22 & 0.33 & 0.19 \\
\hline Beef & 0.17 & 0.17 & 0.16 & 0.13 & 0.19 & 0.18 & 0.19 & 0.19 & 0.16 & 0.16 \\
\hline Pork & 0.16 & 0.14 & 0.20 & 0.17 & 0.26 & 0.17 & 0.24 & 0.19 & 0.19 & 0.15 \\
\hline Fish & 0.17 & 0.17 & 0.19 & 0.13 & 0.21 & 0.15 & 0.21 & 0.20 & 0.16 & 0.17 \\
\hline Eggs & 0.21 & 0.21 & 0.27 & 0.21 & 0.24 & 0.20 & 0.26 & 0.22 & 0.29 & 0.24 \\
\hline Smoked meat and meat products & 0.09 & 0.13 & 0.14 & 0.20 & 0.20 & 0.28 & 0.19 & 0.21 & 0.20 & 0.31 \\
\hline Offal & 0.04 & 0.07 & 0.03 & 0.11 & 0.04 & 0.08 & 0.04 & 0.06 & 0.03 & 0.08 \\
\hline Pulses & 0.16 & 0.18 & 0.16 & 0.13 & 0.19 & 0.18 & 0.17 & 0.18 & 0.17 & 0.14 \\
\hline Fruit group & 1.09 & 0.32 & 1.01 & 0.28 & 1.01 & 0.38 & 1.03 & 0.38 & 1.06 & 0.39 \\
\hline Fruits - fresh & 0.91 & 0.19 & 0.87 & 0.23 & 0.83 & 0.26 & 0.84 & 0.24 & 0.84 & 0.29 \\
\hline Fruits - preserved & 0.17 & 0.25 & 0.14 & 0.14 & 0.19 & 0.21 & 0.19 & 0.25 & 0.21 & 0.27 \\
\hline Vegetable group & 1.80 & 0.51 & 1.59 & 0.58 & 1.50 & 0.50 & 1.61 & 0.59 & 1.50 & 0.56 \\
\hline Vegetables (except potatoes) - raw & 0.50 & 0.36 & 0.50 & 0.35 & 0.54 & 0.34 & 0.63 & 0.33 & 0.56 & 0.34 \\
\hline Vegetables (except potatoes) - cooked & 0.81 & 0.27 & 0.61 & 0.30 & 0.50 & 0.28 & 0.47 & 0.30 & 0.49 & 0.27 \\
\hline Potatoes & 0.49 & 0.25 & 0.47 & 0.22 & 0.46 & 0.22 & 0.51 & 0.23 & 0.46 & 0.21 \\
\hline Grains group & 2.17 & 0.72 & 2.29 & 0.69 & 2.39 & 0.67 & 2.49 & 0.79 & 2.30 & 0.82 \\
\hline Bread & 0.77 & 0.31 & 0.79 & 0.28 & 0.84 & 0.22 & 0.80 & 0.28 & 0.71 & 0.31 \\
\hline Sandwich, buns, rolls & 0.37 & 0.34 & 0.46 & 0.38 & 0.46 & 0.34 & 0.54 & 0.35 & 0.56 & 0.34 \\
\hline Pasta & 0.37 & 0.22 & 0.36 & 0.18 & 0.36 & 0.20 & 0.40 & 0.22 & 0.33 & 0.18 \\
\hline Rice & 0.37 & 0.21 & 0.33 & 0.16 & 0.34 & 0.18 & 0.34 & 0.20 & 0.34 & 0.17 \\
\hline Sweet pastry & 0.29 & 0.25 & 0.36 & 0.25 & 0.39 & 0.26 & 0.40 & 0.27 & 0.36 & 0.30 \\
\hline \multicolumn{11}{|l|}{ Other } \\
\hline Sweets & 0.27 & 0.28 & 0.59 & 0.27 & 0.63 & 0.33 & 0.61 & 0.29 & 0.67 & 0.34 \\
\hline Fried food & 0.04 & 0.06 & 0.11 & 0.11 & 0.14 & 0.14 & 0.16 & 0.08 & 0.19 & 0.09 \\
\hline
\end{tabular}

${ }^{1}$ Including breast-milk

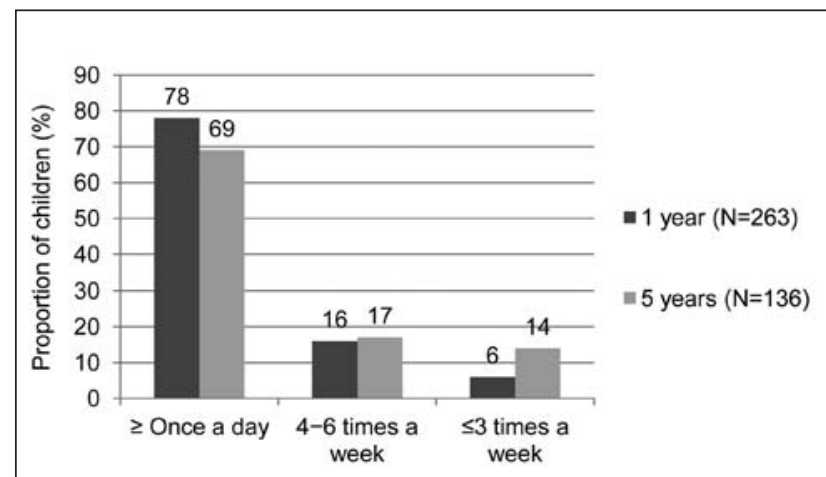

Fig. 1. Distribution of fresh fruits intake frequency at 1 and 5 years of age.

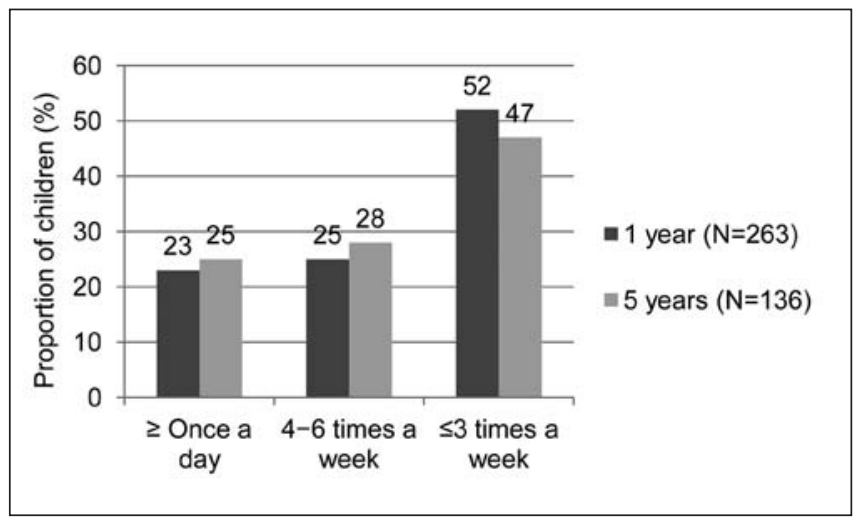

Fig. 2. Distribution of fresh vegetables (except potatoes) intake frequency at 1 and 5 years of age. 
Table 4. Statistically significant changes in daily mean food intake frequency by age

\begin{tabular}{|c|c|c|c|c|c|c|c|c|c|c|c|}
\hline \multirow{2}{*}{$\begin{array}{l}\text { Foods } \\
\text { Milk group }{ }^{1}\end{array}$} & \multicolumn{2}{|c|}{$\begin{array}{l}\text { Between } 1 \text { and } 2 \\
\text { years }\end{array}$} & \multicolumn{2}{|c|}{$\begin{array}{c}\text { Between } 2 \text { and } 3 \\
\text { years }\end{array}$} & $\begin{array}{c}\text { Between } 3 \text { and } 4 \\
\text { years }\end{array}$ & \multicolumn{2}{|c|}{$\begin{array}{c}\text { Between } 4 \text { and } 5 \\
\text { years }\end{array}$} & \multicolumn{2}{|c|}{$\begin{array}{c}\text { Between } 1 \text { and } 3 \\
\text { years }\end{array}$} & \multicolumn{2}{|c|}{$\begin{array}{c}\text { Between } 3 \text { and } 5 \\
\text { years }\end{array}$} \\
\hline & $\downarrow$ & $<0.001$ & & - & - & $\downarrow$ & 0.01 & $\downarrow$ & $<0.001$ & $\downarrow$ & $<0.001$ \\
\hline Milk & & - & & - & - & $\downarrow$ & 0.025 & $\downarrow$ & $<0.001$ & & - \\
\hline $\begin{array}{l}\text { Milk products except } \\
\text { cheese }\end{array}$ & & - & & - & - & $\downarrow$ & 0.008 & & - & $\downarrow$ & 0.001 \\
\hline $\begin{array}{l}\text { Meat, fish, egg, pulses } \\
\text { group }\end{array}$ & & - & & - & - & & - & $\uparrow$ & 0.04 & & - \\
\hline Poultry & & - & & - & - & & - & $\downarrow$ & 0.03 & & - \\
\hline Pork & $\uparrow$ & 0.013 & & - & - & & - & $\uparrow$ & $<0.001$ & & - \\
\hline $\begin{array}{l}\text { Smoked meat and } \\
\text { meat products }\end{array}$ & $\uparrow$ & 0.007 & & - & - & & - & & - & & - \\
\hline Fruit group & $\downarrow$ & 0.003 & & - & - & & - & $\downarrow$ & 0.006 & & - \\
\hline Fruits - fresh & & - & & - & - & & - & $\downarrow$ & 0.013 & & - \\
\hline Vegetable group & & - & $\downarrow$ & 0.004 & - & & - & $\downarrow$ & $<0.001$ & $\downarrow$ & 0.003 \\
\hline $\begin{array}{l}\text { Vegetables (except } \\
\text { potatoes) - cooked }\end{array}$ & $\downarrow$ & $<0.001$ & $\downarrow$ & 0.007 & - & & - & $\downarrow$ & $<0.001$ & & - \\
\hline Grains group & & - & & - & - & & - & $\uparrow$ & 0.014 & & - \\
\hline Bread & & - & & - & - & & - & $\bar{\uparrow}$ & 0.05 & $\downarrow$ & 0.014 \\
\hline Sweet pastry & & - & & - & - & & - & $\uparrow$ & 0.004 & & - \\
\hline \multicolumn{12}{|l|}{ Other } \\
\hline Sweets & & - & & - & - & & - & $\uparrow$ & $<0.001$ & & - \\
\hline Fried food & & - & & - & - & & - & $\uparrow$ & $<0.001$ & & - \\
\hline
\end{tabular}

${ }^{1}$ Including breast-milk

groups - but the proportion of children who took breakfast only sometimes increased with age from $4.6 \%$ in one-year-olds to $28.2 \%$ in five-year-olds.

Mean daily food intake frequency by age is shown in Table 3; statistically significant changes are shown in Table 4. Most statistically significant changes occurred between 1 and 3 years of age. Potatoes account for almost one third (27-31.9\% by age groups) of the vegetable consumption.

Food groups intake frequency distribution by age is shown in Table 5. There were wide variations in the milk group intake frequency at one year of age due to breast-feeding. Most children took the milk two or more times a day. The largest proportion of children 2-4 years of age took the milk 2 to $<3$ times a day, and of five-year-olds 1 to $<3$ times a day. The largest proportion of children took the meat 1 to $<2$ times and grains 1 to $<3$ times a day regardless of age. The largest proportion of children took the vegetable 1 to $<3$ times a day at one year of age and 1 to $<2$ times a day at 2-5 years of age. The largest proportion of children took the fruit 1 to $<2$ times a day regardless of age.

Figures 1-5 illustrate a comparison of selected foods intake frequency distribution at one and five years of age. Fresh fruits were given at least once a day to $78 \%$ of one-year-olds and $69 \%$

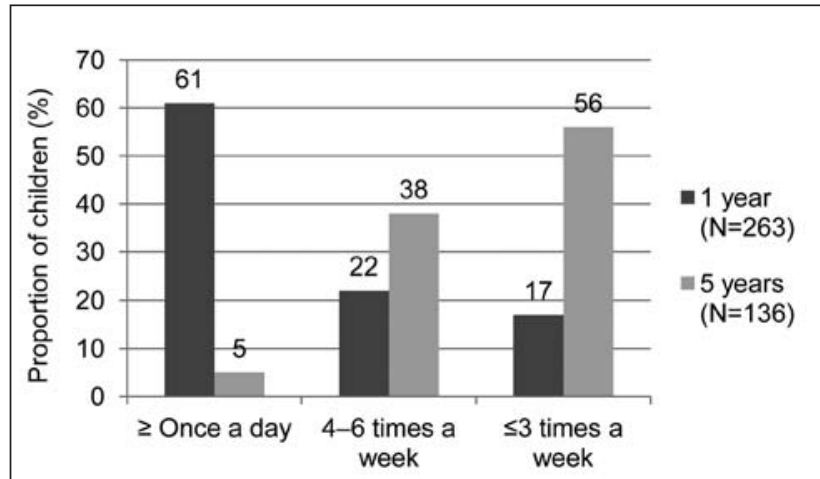

Fig. 3. Distribution of cooked vegetables (except potatoes) intake frequency at 1 and 5 years of age.

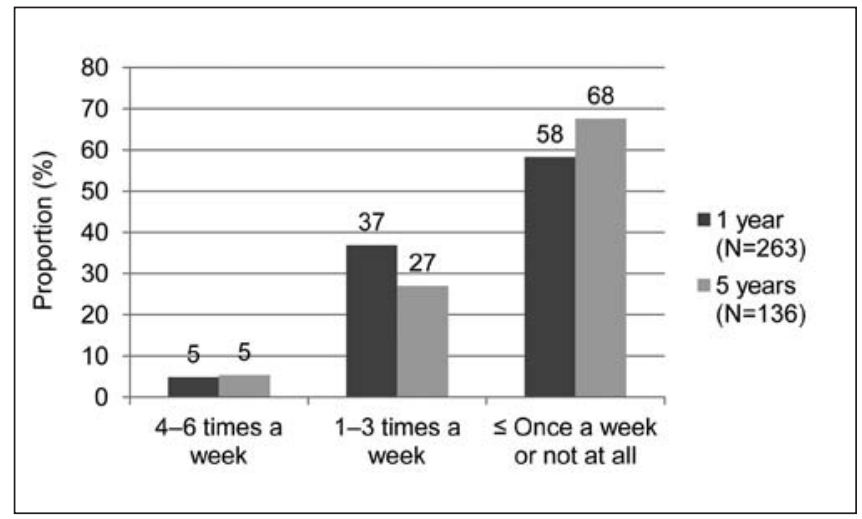

Fig. 4. Distribution of fish intake frequency at 1 and 5 years of age. 
Table 5. Daily food groups intake frequency distribution by age

\begin{tabular}{|c|c|c|c|c|c|c|}
\hline & \multicolumn{6}{|c|}{ Proportion (\%) of children who: } \\
\hline & Do not eat & $\begin{array}{c}\text { Eat }<1 \text { times } \\
\quad \text { a day }\end{array}$ & $\begin{array}{c}\text { Eat } 1-<2 \text { times } \\
\text { a day }\end{array}$ & $\begin{array}{c}\text { Eat } 2-<3 \text { times } \\
\text { a day }\end{array}$ & $\begin{array}{c}\text { Eat } 3-<4 \text { times } \\
\text { a day }\end{array}$ & $\begin{array}{c}\text { Eat } \geq 4 \text { times } \\
\quad \text { a day }\end{array}$ \\
\hline \multicolumn{7}{|l|}{1 year $(\mathrm{N}=263)$} \\
\hline Milk group ${ }^{1}$ & 1.9 & 2.8 & 14.8 & 32.4 & 22.2 & 25.9 \\
\hline Meat, fish, egg, pulses group & 0 & 0 & 80.2 & 17.0 & 2.8 & 0 \\
\hline Vegetable group & 0 & 6.4 & 52.3 & 40.4 & 0.9 & 0 \\
\hline Fruit group & 0.9 & 14.2 & 81.1 & 3.8 & 0 & 0 \\
\hline Grains group & 0 & 4.6 & 44.4 & 38.0 & 12.0 & 0.9 \\
\hline \multicolumn{7}{|l|}{2 years $(\mathrm{N}=228)$} \\
\hline Milk group ${ }^{1}$ & 1 & 0 & 17.3 & 60.6 & 17.3 & 3.8 \\
\hline Meat, fish, egg, pulses group & 0 & 14.4 & 66.3 & 19.2 & 0 & 0 \\
\hline Vegetable group & 0 & 19.0 & 54.3 & 25.7 & 1 & 0 \\
\hline Fruit group & 1 & 22.3 & 76.7 & 0 & 0 & 0 \\
\hline Grains group & 0 & 4.8 & 37.1 & 46.7 & 10.5 & 1.0 \\
\hline \multicolumn{7}{|l|}{3 years $(\mathrm{N}=263)$} \\
\hline Milk group & 0.9 & 3.7 & 19.6 & 59.8 & 15.9 & 0 \\
\hline Meat, fish, egg, pulses group & 0.9 & 19.6 & 53.3 & 22.4 & 3.7 & 0 \\
\hline Vegetable group & 0 & 17.8 & 58.9 & 23.4 & 0 & 0 \\
\hline Fruit group & 4.7 & 29 & 66.4 & 0 & 0 & 0 \\
\hline Grains group & 0 & 0.9 & 30.8 & 52.3 & 13.1 & 2.8 \\
\hline \multicolumn{7}{|l|}{4 years $(\mathrm{N}=240)$} \\
\hline Milk group & 4.7 & 4.7 & 17.9 & 50.9 & 21.7 & 0 \\
\hline Meat, fish, egg, pulses group & 0 & 18.3 & 60.6 & 18.3 & 2.9 & 0 \\
\hline Vegetable group & 0 & 21 & 47.6 & 31.4 & 0 & 0 \\
\hline Fruit group & 1.9 & 27.6 & 65.7 & 4.8 & 0 & 0 \\
\hline Grains group & 0 & 0.9 & 30.8 & 52.3 & 13.1 & 2.8 \\
\hline \multicolumn{7}{|l|}{5 years $(\mathrm{N}=136)$} \\
\hline Milk group & 5.1 & 7.7 & 38.5 & 43.6 & 5.1 & 0 \\
\hline Meat, fish, egg, pulses group & 0 & 22.9 & 60 & 17.1 & 0 & 0 \\
\hline Vegetable group & 0 & 18.9 & 62.2 & 18.9 & 0 & 0 \\
\hline Fruit group & 5.3 & 21.1 & 73.7 & 0 & 0 & 0 \\
\hline Grains group & 0 & 7.9 & 42.1 & 36.8 & 13.2 & 0 \\
\hline
\end{tabular}

${ }^{1}$ Including breast-milk

Table 6. First and second most frequently taken beverages by age (proportion [\%] of children taking the beverage as the first or second most frequent)

\begin{tabular}{|l|c|c|c|c|c|}
\hline & 1 year $(\mathrm{N}=263)$ & 2 years $(\mathrm{N}=228)$ & 3 years $(\mathrm{N}=263)$ & 4 years $(\mathrm{N}=240)$ & 5 years $(\mathrm{N}=136)$ \\
\hline Tea & 73.7 & 70.2 & 71.6 & 62.9 & 65.0 \\
\hline Milk & 46.4 & 49 & 40.9 & 33.3 & 15.5 \\
\hline Juice & 49.5 & 32.4 & 50.0 & 62.9 & 39.4 \\
\hline Water, mineral water & 24.5 & 22.1 & 25.0 & 31.4 & 31.0 \\
\hline
\end{tabular}

of five-year-olds; fresh vegetables to $23 \%$ of one-year-olds and $25 \%$ of five-year-olds; cooked vegetables to $61 \%$ of one-yearolds but only to $5 \%$ of five-year-olds. Fish were given at least once a week to $42 \%$ of one-year-olds and $32 \%$ of five-year-olds. Smoked meat and meat products were given once a week or more frequently to $16 \%$ of one-year-olds and $32 \%$ of five-year-olds (4 


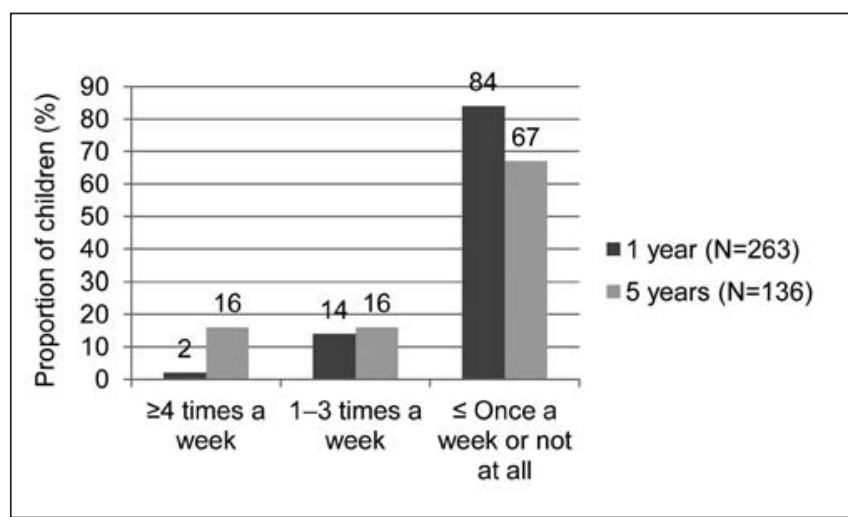

Fig. 5. Distribution of smoked meat and meat products intake frequency at 1 and 5 years of age.

or more times a week to $16 \%$ ). The proportion of children who were given wholemeal grain products slowly increased with age (Fig. 6). The proportion of children who were given low fat milk and milk products ranged between 15 and $27 \%$ in age groups, did not show an age trend, and was highest at one year of age.

The comparison of food intake frequencies in one year old children by breast-feeding status at the time of the interview has shown that breast-fed children took more frequently the vegetable group ( 1.7 and 1.9 times a day respectively, $p=0.01)$ and fish less frequently ( 0.1 and 0.2 times a day respectively, $p=0.03$ ) than the non-breast-fed children. Higher fruit group intake frequency in breast-fed than non-breast-fed children was near statistical significance ( 1.2 and 1 times a day respectively, $\mathrm{p}=0.06$ ).

One and two year old girls took foods from the grains group more frequently than boys (at one year: 2.2 and 1.9 times a day respectively, $\mathrm{p}=0.04$; at two years 2 and 1.9 times a day respectively, $\mathrm{p}=0.05$ ), five year old girls took foods from the vegetable group without potatoes more frequently than boys ( 1.3 and 0.8 times a day respectively, $\mathrm{p}=0.048$ ), and foods from the meat group less frequently than boys ( 1.3 and 1.6 times a day respectively, $\mathrm{p}=0.04$ ).

One year old children of mothers - university graduates - took foods from the vegetable group more frequently than those of mothers with lower education (1.9 and 1.6 times a day respectively, $\mathrm{p}=0.003$ ) and foods from the grain group less frequently ( 2 and 2.3 times a day respectively, $\mathrm{p}=0.001$ ).

One year old children living in Prague took the fruit group more frequently than children living elsewhere (1.2 and 1 times a day respectively, $\mathrm{p}=0.06$ ), preserved fruits significantly less frequently ( 0.3 and 0.1 times a day respectively, $p=0.001$ ), the meat group more frequently ( 1.5 and 1.2 times a day respectively, $\mathrm{p}=0.002)$, and also poultry more frequently $(0.4$ and 0.5 times a day respectively, $\mathrm{p}=0.003$ ).

Five year old children from Prague took beef $(0.2$ and 0.1 times a day respectively, $\mathrm{p}=0.003)$ and pork $(0.2$ and 0.1 times a day respectively, $\mathrm{p}=0.003$ ) more frequently than children living elsewhere, and potatoes less frequently ( 0.6 and 0.4 times a day respectively, $\mathrm{p}=0.002$ ).

There was no other significant difference in the food intake frequency by breast-feeding status, sex, maternal education, or domicile.

Mothers were asked in an open ended question to name two most frequently taken beverages. Tea, milk, juice, and water or

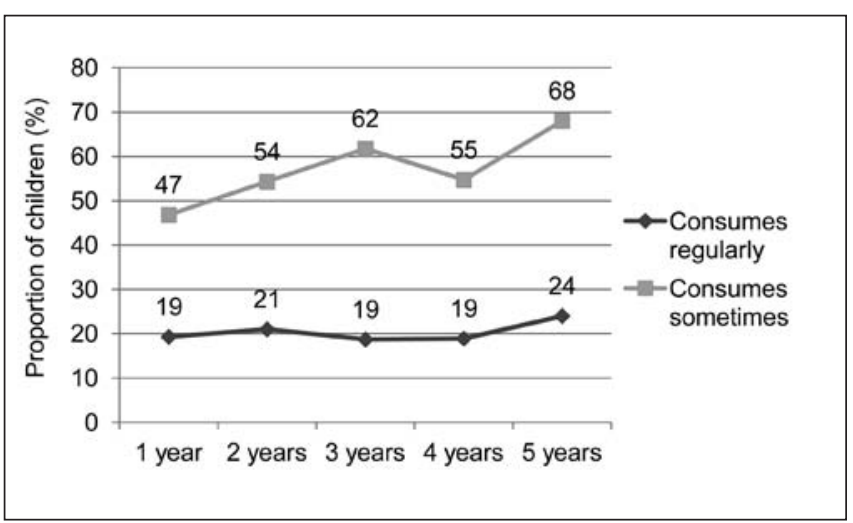

Fig. 6. Wholemeal products consumption by age.

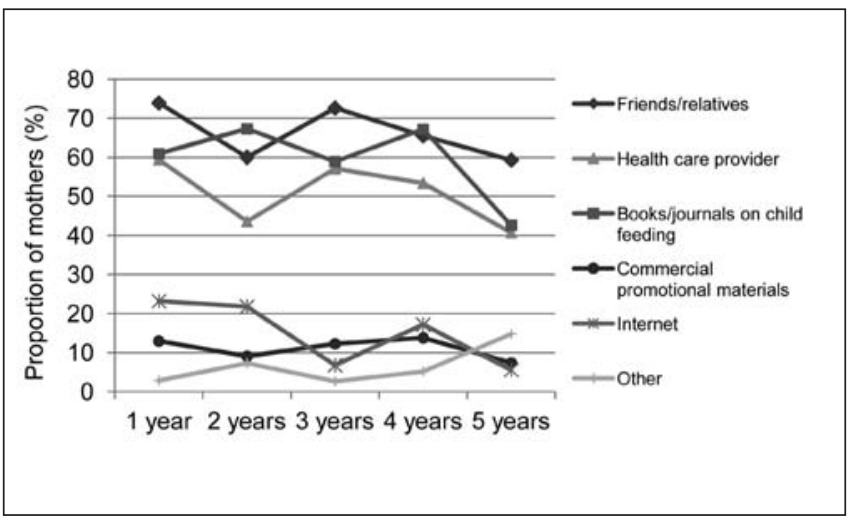

Fig. 7. Maternal source of advice on child feeding (many mothers reported more than one source of advice).

mineral water were the first and second most frequently taken beverages in all age groups (Table 6). Tea was the most frequent beverage in all age groups. Most mothers did not specify the type of tea given, however, the type of tea was specified as fruit, herbal or "for children" in $25.7 \%$ one-year-olds; the specification decreased with age to $1.4 \%$ in 5 years old children. Black tea was explicitly mentioned by two mothers only. Milk was, after tea, the second most frequent beverage in one and two years old children (breast milk for $9.2 \%$ of one year old children), then it was surpassed by juice. Water was the 4th most frequent beverage in all age groups.

Relatives or friends, health care providers, and child care books or journals were the most frequent sources of information about child feeding (Fig. 7). Mothers usually reported more than one sources of information -1.9 source in average.

\section{DISCUSSION}

Eating habits important for one's long term health status develop early in life (11). Parents and caregivers play an important role in forming the dietary habits in early childhood. A child at this age is still fully dependent for food on his or her carers who thus influence his or her future eating habits and through them his/her health. A dietary pattern that is low in fruits, vegetables, 
and wholegrain products and high in fat, sugars, and salt has been associated with non-communicable diseases such as obesity, cardiovascular diseases, and some types of cancer. Adequate fruit and vegetables intake is associated with lower risk of these diseases (12).

The obtained data illustrate positive features of toddlers' and pre-schoolers' diet, while concerns exist in the following areas: delayed introduction of recommended meal frequency at one year of age, lower than desirable meal frequency at 5 years of age, proportion of children who do not take breakfast regularly increasing with age, low and with age further decreasing fruit and vegetable intake frequency, and smoked meat and meat products, sweets, and fried food intake frequency increasing with age and low fish consumption. The somewhat more favourable dietary patterns of children breast-fed beyond one year may have several explanations, e.g. higher maternal education of breast-fed children shown in this study or easier acceptance of a variety of foods by breastfed children described in literature (11).

Of great importance is breast-feeding of $29.5 \%$ of children beyond one year of age and of $7 \%$ even beyond two years of age as recommended by WHO (13). Breast-feeding is an unequalled way of providing ideal food for the healthy growth and development of children and it is also an integral part of the reproductive process with important implications for mothers health (13). The duration of breast-feeding in the Czech Republic remarkably increased since the activities supporting and promoting breastfeeding, especially the Baby-Friendly Hospital Initiative, started to gain momentum at the beginning of the 1990s' (14).

The introduction of recommended meal frequency appeared to be delayed - the median number of meals and snacks of children aged one year was 4 and $18.8 \%$ of children got food other than milk only 2-3 times a day. The median number of meals and snacks per day at 2-4 years of age was consistent with the recommendation to eat 5 times a day (15), at 5 years of age it decreased to 4 . Evidence suggests a significant reduction of obesity risk with increasing number of meals and therefore it appears prudent to promote a regular meal pattern with 5 meals per day with adequate composition to children and their families (16). Skipping breakfast, a well-known negative habit in children in various populations (17), was rare in our study but of concern is the proportion of children who take breakfast only sometimes increasing with age to $28.2 \%$ at five years. The results of a recent systematic review suggest that eating breakfast is associated with a reduced risk of becoming overweight or obese in childhood and adolescence (17) and also may have detrimental effects on cardio metabolic health (18).

Although frequency of fruit and vegetable consumption was somewhat lower than recommended and $6.4 \%$ children did not eat fruits and $15.1 \%$ did not eat vegetables daily, the diet at one year of age was the closest to the recommendations among all age groups. Most of the statistically significant changes occurred between one and three years of age. The intake frequency of fiveyear-olds in our study was similar, in some foods remarkably so, to the intake frequency of 11 years old children in Brno (19) thus confirming that eating habits are formed early in life (11).

The frequency of vegetable consumption statistically significantly decreased between two and three years of age. The proportion of children who did not eat any vegetables daily ranged between $18 \%$ and $21 \%$ by age groups from 2 years of age.
Consumption of cooked and fresh vegetables (except potatoes) of our five-year-olds was very similar to the consumption of 11 years old children in Brno (19): only 3\% of our five-year-olds and $5 \%$ of 11 -year-olds in Brno consumed cooked vegetables at least once a day and only $25 \%$ of our five-year-olds and $24 \%$ of 11 -year-olds in Brno consumed raw vegetables at least once a day. Higher vegetable consumption was associated with breastfeeding and maternal university education at 1 year of age, and female sex at 5 years of age in our study.

Fruit consumption decreased significantly between 1 and 2 years of age and the proportion of children who did not eat fruit daily ranged between $23 \%$ and $34 \%$ by age groups. In the Brno study (19), the fruit consumption at least once a day in 11-yearolds was still somewhat lower (50\%) than that of five-year-olds in our study (69\%). Unlike in other studies showing a preference for fruits at this age $(20,21)$, consumption of vegetables in our study was higher than that of fruits. This is mainly due to potatoes that are generally consumed frequently and in our study contributed substantially to the vegetable intake frequency, accounting for approximately one third of vegetable group consumption. Higher fruit group consumption was associated with breast-feeding and living in Prague; higher preserved fruit consumption was associated with living out of Prague. Other studies have also shown that breast-feeding duration predicts fruit consumption (22). The finding of less than adequate fruit and vegetable intake is in line with other studies $(20,21,22)$ and of concern as adequate fruit and vegetables intakes are especially important as diets rich in these foods have numerous health benefits $(12,23)$. According to the European Society for Paediatric Gastroenterology, Hepatology, and Nutrition (ESPGHAN), plant foods can be used as the main food contributors to a well-balanced diet (24).

Mean milk group intake frequency was in accordance with the recommended number of servings at 2 and 4 years of age and lower than recommended in 3 and 5-year-olds. Low or reduced fat milk or milk products were given to approximately one quarter of children below 2 years of age, which is not consistent with recommendations - low or reduced fat products should not be given to children below 2 years of age (15).

Mean meat group intake frequency was in accordance with recommended 1-2 servings (25) in all age groups. Higher meat group consumption was associated with male sex at 5 years of age. The fish intake frequency was low at all ages. It is critical to include foods such as fish and food made with vegetable oils to help to achieve the right balance of fat for toddlers and pre-schoolers. Decrease in poultry consumption and increase in pork consumption with age leads to the increase of hidden fats in food. On the other hand, iron content of pork is higher than of poultry. The intake frequency of smoked meat and meat products statistically significantly increased already in the second year of life. It certainly is positive that $61 \%$ of one-year-olds and $51 \%$ of five-year-olds consumed smoked meat and meat products rarely but it is startling that $16 \%$ of five-year-olds consumed it 4 times a week or more frequently. This may be partly due to the consumption of ham, which is usually considered acceptable for children. Also fried foods that add to fat intake were offered more frequently with increasing age.

Mean grain group intake frequency was lower than recommended in all age groups (15). Regular consumption of wholemeal grain products did not change considerably with age and was low 
(19-24\% by age groups), occasional consumption increased with age to $68 \%$ at 5 years.

A negative feature is the increase of sweets (desserts, candies) consumption with age, which increases the amount of extrinsic sugar consumed. Our five-year-olds got these food items 4.7 times per week, which was again similar with 11-year-olds in Brno (19): the intake frequency of category of chocolate, cakes and other sweets was 5 times a week. In addition, the consumption of sweet pastry in the grain groups also increased.

The intake of free sugar from sweetened tea and fruit juice may be potentially problematic although the association of excessive fruit juice intake ( $>350 \mathrm{~mL} /$ day) with short stature and obesity in preschool children found in one study (26) has not been confirmed by later studies $(27,28,29)$.

Mothers reported multiple and concurrent information sources about child feeding practices. Thus, nutrition educators have concurrent and multiple opportunities to disseminate nutrition information.

This research has a number of limitations and the results of this study must therefore be interpreted with caution. Respondents were a convenience sample in which the children living in Prague were overrepresented and the children from regions were underrepresented. As the mothers were recruited in public places, the children included into the study were healthy and did not attend pre-school establishments at all or at least not full time. This has undoubtedly influenced the prevalence of breast-feeding and may have influenced other feeding habits. The dietary information was mother-reported and therefore associated with the reporting biases inherent in dietary reporting: retrospective reporting relied upon the mother's memory, the intake frequency of foods perceived as healthy may have been overestimated and that of foods perceived as not healthy underestimated, and/or the groupings of foods may have not corresponded to the perception of respondent. And, finally, some of the statistically significant findings reported here may have been due to chance.

\section{CONCLUSIONS}

Parents and caregivers play an important role in forming the dietary habits in early childhood. A child at this age is still fully dependent for food on his or her carers who thus influence his or her future eating habits and through them his/her health. Our data confirm other studies findings that the dietary habits are formed early in life. The findings presented here provide important inputs to the content of messages that are needed to improve the feeding practices of toddlers and pre-schoolers. Longer duration of breast-feeding is a positive feature to which further enhancement of breast-feeding counselling could still contribute. Despite the less than optimal consumption of vegetables and fruits, the data appear to indicate that parents get and follow correct nutrition messages for feeding of infants from the health workers and other sources. This is reflected in the feeding pattern of one year old children.

The dietary habits of $2-5$ year old children showed a perceptible trend to shortcomings that occur in the diet of older children and adults in the Czech Republic as well as in other industrial countries. In order to improve the dietary habits of toddlers and pre-schoolers, it is desirable to enhance health care providers advice and public health messages for toddlers and pre-schoolers and also to focus the nutrition messages on the improvement of family eating habits as small children tend to take over the parental food preferences.

\section{Acknowledgements}

We are grateful to all mothers who took part in this study. We would like to acknowledge the dedicated work of the 5 th year students of the 1 st Faculty of Medicine, Charles University of Prague, who conducted the interviews and collected the data (but declined the offer to participate in developing this article). Our great thanks also go to Mrs Krikavova who computerized the data.

\section{REFERENCES}

1. World Health Organization. Diet, nutrition and the prevention of chronic diseases. Geneva: WHO; 2003.

2. St-Onge MP, Keller KL, Heymsfield SB. Changes in childhood food consumption patterns: a cause for concern in light of increasing body weights. Am J Clin Nutr. 2003 Dec;78(6):1068-73.

3. Golan M. Parents as agents of change in childhood obesity - from research to practice. Int J Pediatr Obes. 2006;1(2):66-76.

4. Hodges EA. A primer on early childhood obesity and parental influence. Pediatr Nurs. 2003 Jan-Feb;29(1):13-6.

5. Rowett Research Institute. Family diet and health in pre-war Britain. Carnegie United Kingdom Trust; 1955.

6. van der Pols JC, Gunnell D, Williams GM, Holly JM, Bain C, Martin RM. Childhood dairy and calcium intake and cardiovascular mortality in adulthood: 65-year follow-up of the Boyd Orr cohort. Heart. 2009 Oct;95(19):1600-6.

7. Maynard M, Gunnell D, Ness AR, Abraham L, Bates CJ, Blane D. What influences diet in early old age? Prospective and cross-sectional analyses of the Boyd Orr cohort. Eur J Public Health. 2006 Jun;16(3):315-23.

8. Ip S, Chung M, Raman G, Chew P, Magula N, DeVine D, et al. Breastfeeding and maternal and infant health outcomes in developed countries. Evid Rep Technol Assess (Full Rep). 2007 Apr;(153):1-186.

9. Fewtrell MS. The long-term benefits of having been breast-fed. Current Paediatrics. 2004 Apr;14(2):97-103.

10. StatSoft, Inc. Statistica (data analysis software system), version 9.1. [Internet]. Tulsa: StatSoft, Inc.; 2010 [cited 2012 Apr 30]. Available from: http://www.statsoft.com.

11. Birch LL. Development of food acceptance patterns in the first years of life. Proc Nutr Soc. 1998 Nov;57(4):617-24.

12. World Health Organization. Global strategy on diet, physical activity and health. Geneva: WHO; 2004.

13. World Health Organization. Global strategy on infant and young child feeding. Geneva: WHO; 2002.

14. Institute of Health Information and Statistics of the Czech Republic. Activities of health care services in selected fields of curative-preventive care 2000-2009 [Internet]. Prague: Institute of Health Information and Statistics of the Czech Republic; 2011 [cited 2011 Jun 25]. Available from: http://www.uzis.cz/katalog/zdravotnicka-statistika/cinnost-zdravotnickych-zarizeni-vybranych-oborech. (In Czech.)

15. Nevoral, J. Cepova J, Feber J, Fruhauf P, Hyanek J, Janda J, et al. Nutrition in childhood. Prague: H\&H; 2003. (In Czech.)

16. Koletzko B, Toschke AM. Meal patterns and frequencies: do they affect body weight in children and adolescents? Crit Rev Food Sci Nutr. 2010 Feb;50(2):100-5.

17. Szajewska H, Ruszczynski M. Systematic review demonstrating that breakfast consumption influences body weight outcomes in children and adolescents in Europe. Crit Rev Food Sci Nutr. 2010 Feb;50(2):113-9.

18. Smith KJ, Gall SL, McNaughton SA, Blizzard L, Dwyer T, Venn AJ. Skipping breakfast: longitudinal associations with cardiometabolic risk factors in the Childhood Determinants of Adult Health Study. Am J Clin Nutr. 2010 Dec;92(6):1316-25.

19. Fiala J, Kukla L, Poslušná K. The diet structure of 11-years old children - The ELSPAC study. Čes-slov Pediat. 2008;63(9):481-90. 
20. Gibson EL, Wardle J, Watts CJ. Fruit and vegetable consumption, nutritional knowledge and beliefs in mothers and children. Appetite. 1998 Oct;31(2):205-28.

21. Siega-Riz AM, Deming DM, Reidy KC, Fox MK, Condon E, Briefel RR. Food consumption patterns of infants and toddlers: where are we now? J Am Diet Assoc. 2010 Dec;110(12 Suppl):S38-51.

22. Skinner JD, Carruth BR, Bounds W, Ziegler P, Reidy K. Do food-related experiences in the first 2 years of life predict dietary variety in schoolaged children? J Nutr Educ Behav. 2002 Nov-Dec;34(6):310-5.

23. Heidemann C, Schulze MB, Franco OH, van Dam RM, Mantzoros CS, $\mathrm{Hu}$ FB. Dietary patterns and risk of mortality from cardiovascular disease, cancer, and all causes in a prospective cohort of women. Circulation. 2008 Jul 15;118(3):230-7.

24. ESPGHAN Committee on Nutrition, Agostoni C, Braegger C, Decsi T, Kolacek S, Koletzko B, Mihatsch W, et al. Role of dietary factors and food habits in the development of childhood obesity: a commentary by the ESPGHAN Committee on Nutrition. J Pediatr Gastroenterol Nutr. 2011 Jun;52(6):662-9.

25. Müllerová D. Healthy nutrition and prevention of civilization diseases in schemes. Prague: Triton; 2003. (In Czech.)
26. Dennison BA, Rockwell HL, Baker SL. Excess fruit juice consumption by preschool-aged children is associated with short stature and obesity. Pediatrics. 1997 Jan;99(1):15-22. Erratum in: Pediatrics. 1997 Oct;100(4):733.

27. Skinner JD, Carruth BR, Moran J 3rd, Houck K, Coletta F. Fruit juice intake is not related to children's growth. Pediatrics. 1999 Jan;103(1):5864.

28. O`Connor TM, Yang SJ, Nicklas TA. Beverage intake among preschool children and its effect on weight status. Pediatrics. 2006 Oct;118(4):e1010-8.

29. Alexy U, Sichert-Hellert W, Kersting M, Manz F, Schöch G. Fruit juice consumption and the prevalence of obesity and short stature in german preschool children: results of the DONALD Study. Dortmund Nutritional and Anthropometrical Longitudinally Designed. J Pediatr Gastroenterol Nutr. 1999 Sep;29(3):343-9.

Received July 1, 2011 Accepted in revised form March 1, 2012 